\title{
Reoperative "valve-in-valve" transapical transcatheter mitral valve replacement in a high-risk patient with a recent transapical transcatheter aortic valve replacement and a degenerated bioprosthetic mitral valve
}

\author{
Andreas R. de Biasi, MD, ${ }^{\text {a }}$ Shing-Chiu Wong, MD, ${ }^{\mathrm{b}}$ and Arash Salemi, MD, ${ }^{\mathrm{a}}$ New York, NY
}

Transapical transcatheter aortic valve replacement (TAAVR) can safely be performed in high-risk patients who are not candidates for conventional replacement. However, using the transapical transcatheter (TA) approach as a reoperative strategy in patients who have undergone previous TA valve surgery has not been well described. We therefore report the first known case of a patient who recently underwent TA-AVR and subsequently developed severe prosthetic mitral regurgitation that was managed with a "valve-invalve" TA mitral valve (MV) replacement.

\section{CASE REPORT}

An 85-year-old man with a complex history notable for coronary artery disease status post $(\mathrm{s} / \mathrm{p})$ multiple percutaneous coronary interventions and a 2-vessel bypass 14 years previously, MV disease $\mathrm{s} / \mathrm{p}$ bioprosthetic valve replacement (concomitant with the bypass), aortic stenosis s/p TA-AVR 4 months previously, ventricular tachycardia $\mathrm{s} / \mathrm{p}$ biventricular implantable cardioverter-defibrillator, atrial fibrillation (on warfarin), and chronic kidney disease presented to a community hospital complaining of progressively worsening dyspnea. The patient underwent diuresis and ultimately was transferred to our center, where transthoracic echocardiography revealed new 4+ mitral regurgitation and thickened, calcified bioprosthetic mitral cusps.

The patient's condition deteriorated, and he was transferred to the cardiac intensive care unit for ionotropic support and continuous venovenous hemofiltration. An intra-aortic balloon pump had to be placed, and inhaled nitric oxide was started. However, the patient's profound

\footnotetext{
From the Departments of Cardiothoracic Surgery ${ }^{\mathrm{a}}$ and Medicine, ${ }^{\mathrm{b}}$ Weill Cornell Medical College, New York, NY.

Disclosures: Dr Wong is a member of the speakers' bureau and advisory board of Medtronic. All other authors have nothing to disclose with regard to commercial support.

Received for publication July 10, 2014; accepted for publication July 14, 2014; available ahead of print Aug 16, 2014.

Address for reprints: Arash Salemi, MD, Department of Cardiothoracic Surgery, Weill Cornell Medical College, 525 E 68th St, M-404, New York, NY 10065 (E-mail: ars9001@med.cornell.edu).

J Thorac Cardiovasc Surg 2014;148:e209-10

$0022-5223 / \$ 36.00$

Copyright (C) 2014 by The American Association for Thoracic Surgery

http://dx.doi.org/10.1016/j.jtcvs.2014.07.011
}

cardiogenic shock worsened. His predicted risk of mortality (Society of Thoracic Surgeons risk score) from conventional MV replacement was $87 \%$. Given his desire to proceed with the maximal efforts of care, we brought the patient to the operating room for emergency TA "valve-in-valve" MV replacement after he had provided informed consent.

A $10-\mathrm{cm}$ anterolateral incision was made overlying the ventricular apex. The left ventricle was accessed $1 \mathrm{~cm}$ inferior to the previous TA entry site by way of an 18-gauge needle, through which a guide wire was then passed. The regurgitant $27-\mathrm{mm}$ bioprosthetic MV was crossed without difficulty. Using the Seldinger technique and the Ascendra+ System (Edwards Lifesciences, Irvine, Calif), a new 26-mm SAPIEN valve (Edwards Lifesciences) was retrogradely deployed through the old bioprosthesis. Intraoperative angiography and transesophageal echocardiography both confirmed excellent MV bioprosthesis placement with proper valvular function and trace regurgitation (Figure 1). The patient was then transported to the cardiothoracic surgery intensive care unit critically ill but with improved hemodynamics.

The patient showed remarkable improvement over the next several days. The intra-aortic balloon pump was removed on postoperative day (POD) 1 , and he was weaned off the inhaled nitric oxide and vasopressors. His renal function began to improve, and continuous venovenous hemofiltration was suspended on POD 9. The patient was transferred to a step-down unit on POD 15 and was discharged to a subacute rehabilitation facility on POD 19. His transthoracic echocardiogram at discharge showed the MV bioprosthesis remained in a good position, with a valve area of $1.8 \mathrm{~cm}^{2}$ and a gradient of $6 \mathrm{~mm} \mathrm{Hg}$; trace mitral regurgitation was present. At 6 months after surgery, the patient was walking short distances, denied dyspnea at rest, and was comfortably living at home. His transthoracic echocardiogram demonstrated a well-positioned, properly functioning MV with mild paravalvular regurgitation. He had no evidence of a ventricular apex aneurysm.

\section{DISCUSSION}

High-risk patients requiring reoperative valve surgery in the setting of previous TA-AVR pose a surgical 


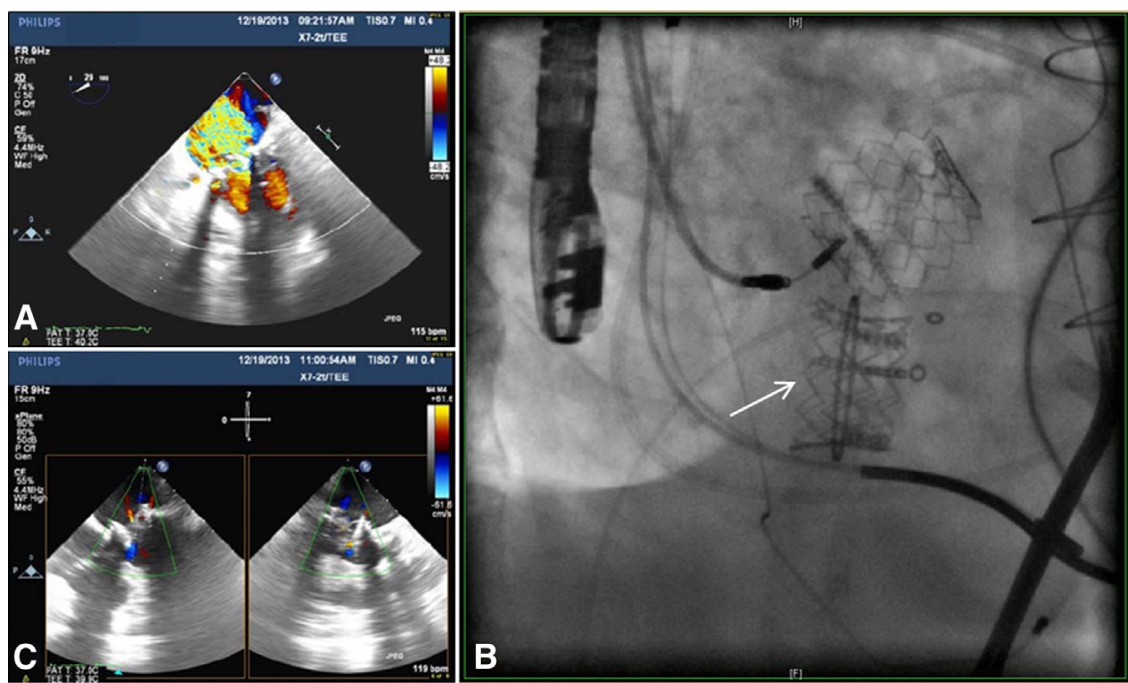

FIGURE 1. A, Previous mitral valve bioprosthesis with evidence of severe regurgitation on transesophageal echocardiogram. B, New "valve-in-valve" bioprosthesis (arrow) deployed using a transapical transcatheter approach demonstrating nonobstructive flow on transesophageal echocardiogram, with (C) trace regurgitation.

dilemma: Widely held, largely anecdotal dogma holds that re-entering the apex in this scenario comes with undue risk and that redo TA approaches should therefore not be entertained. To date, only 2 such redo operations have been described. ${ }^{1,2}$ The first case involved a reoperative TA-AVR performed 3 years after the index procedure; the original TA-placed bioprosthesis had deteriorated, necessitating replacement. ${ }^{1}$ In the second description, redo TA-AVR was performed more acutely (ie, 1 day) after an initial TA-AVR resulted in grade 2 paravalvular regurgitation. ${ }^{2}$ Both of these reports used "valve-in-valve" replacements and demonstrated that such repeat operations are feasible.

The present case is unique in that we performed a reoperative TA valve replacement with a bioprosthesis used in the mitral position-a prosthesis actually designed for the native aortic position. Although surgeons have already accessed the MV using the TA approach (for both native and prosthetic valve replacements), none have done so by re-entering an apex that had previously been subjected to a TA procedure. ${ }^{3,4}$

\section{CONCLUSIONS}

A high perioperative risk often precludes conventional reoperative MV replacement. Moreover, previous TAAVR is considered to be a contraindication to redo TA surgery. We have demonstrated that TA replacement of a failed MV bioprosthesis can be safely performed in a patient who had undergone previous TA-AVR. Despite his precarious risk profile, our patient continues to do well postoperatively.

\section{References}

1. Kiefer P, Seeburger J, Chu MW, Ender J, Vollroth M, Noack T, et al. Reoperative transapical aortic valve implantation for early structural valve deterioration of a SAPIEN XT valve. Ann Thorac Surg. 2013;95:2169-70.

2. Ferrari E, Locca D, Marcucci C, Jeanrenaud X. Urgent reoperative transapical valve-in-valve shortly after a transapical aortic valve implantation. Eur J Cardiothorac Surg. November 28, 2013 [Epub ahead of print].

3. Hasan R, Mahadevan VS, Schneider H, Clarke B. First in human transapical implantation of an inverted transcatheter aortic valve prosthesis to treat native mitral valve stenosis. Circulation. 2013;128:e74-6.

4. Wilbring M, Alexiou K, Tugtekin SM, Arzt S, Ibrahim K, Matschke K, et al. Pushing the limits - further evolutions of transcatheter valve procedures in the mitral position, including valve-in-valve, valve-in-ring, and valve-in-native-ring. J Thorac Cardiovasc Surg. 2014;147:210-9. 